\title{
Erratum to: In vitro generated anti-tumor $T$ lymphocytes exhibit distinct subsets mimicking in vivo antigen-experienced cells
}

Shicheng Yang $\cdot$ Luca Gattinoni $\cdot$ Fang Liu •

Yun Ji $\cdot$ Zhiya Yu $\cdot$ Nicholas P. Restifo •

Steven A. Rosenberg $\cdot$ Richard A. Morgan

Published online: 2 March 2011

(C) Springer-Verlag 2011

Erratum to: Cancer Immunol Immunother

DOI 10.1007/s00262-011-0977-7

Unfortunately, in the published article, the second author's first and last names were interchanged, as Gattinoni Luca.

The correct name should be Luca Gattinoni.

The online version of the original article can be found under doi:10.1007/s00262-011-0977-7.

S. Yang $\cdot$ L. Gattinoni $\cdot$ F. Liu $\cdot$ Y. Ji $\cdot$ Z. Yu

N. P. Restifo · S. A. Rosenberg · R. A. Morgan ( $\square)$

Surgery Branch, Center for Cancer Research, National Cancer

Institute, National Institutes of Health, 10 Center Drive,

Building 10, CRC 3W-3864, Bethesda, MD 20892, USA

e-mail: rmorgan@mail.nih.gov 